\title{
Effective Use of Sugammadex for Incomplete Pyridostigmine Reversal of Muscle Relaxation by Rocuronium: A Case Report
}

\section{Hee Jong Lee, Kyo Sang Kim*, Ji Seon Jeong, Sung Hwan Choi, Kyu Nam Kim}

Department of Anesthesiology and Pain Medicine, Hanyang University Hospital, Seoul, South Korea.

Email: *kimks@hanyang.ac.kr

Received September $3^{\text {rd }}, 2013$; revised September $28^{\text {th }}, 2013$; accepted October $11^{\text {th }}, 2013$

Copyright (C) 2013 Hee Jong Lee et al. This is an open access article distributed under the Creative Commons Attribution License, which permits unrestricted use, distribution, and reproduction in any medium, provided the original work is properly cited.

\begin{abstract}
Anticholinesterase does not allow adequate reversal of the deep neuromuscular blockade (NMB) achieved using high doses of relaxants. A 71-year-old female patient (weight $70 \mathrm{~kg}$, height $169 \mathrm{~cm}$ ) was scheduled for a transurethral resection of a bladder tumor under general anesthesia. We administered rocuronium $30 \mathrm{mg}(0.43 \mathrm{mg} / \mathrm{kg})$ for tracheal intubation due to an estimated short surgical time. During the operation, an additional rocuronium $10 \mathrm{mg}$ was injected. The surgical procedure ended abruptly 10 minutes after receiving the last dose of rocuronium. At the end of surgery, the patient received pyridostigmine as a reversal. However, residual NMB persisted, and neuromuscular monitoring did not show the expected degree of recovery. Sugammadex $2 \mathrm{mg} / \mathrm{kg}$ was used, and the patient experienced complete reversal from NMB in just 2 min.
\end{abstract}

Keywords: Pyridostigmine; Residual Block; Rocuronium; Sugammadex

\section{Introduction}

Neostigmine is widely used in many countries, but a high frequency $(32 \%)$ of residual block (train-of-four (TOF) ratios $<0.9)$ was noted after the use of intermediateacting neuromuscular blockade (NMB) drugs in a postanesthesia care unit [1]. Pyridostigmine is frequently used as reversal agent for rocuronium-induced NMB only in Korea [2]. Pyridostigmine is preferred for its longer duration of action compared with neostigmine or edrophonium, although the onset of pyridostigmine is slower [3]. However, there is a high risk of significant residual neuromuscular block after rocuronium even with reversal using a large dose of pyridostigmine in the recovery room [4]. Recent reports indicate that sugammadex, a modified $\gamma$-cyclodextrin, is highly effective for reversal of deep or moderate NMB induced by steroidal agents [5]. We report a case of successful reverse by sugammadex after previous administration of pyridostigmine that resulted in incomplete reversal of deep rocuronium-induced NMB.

${ }^{*}$ Corresponding author.

\section{Case Report}

A female patient, 71 years old, $70 \mathrm{~kg}, 169 \mathrm{~cm}$, ASA II, was scheduled for transurethral resection under general anesthesia of a malignant bladder tumor located on the dome of the bladder. She had a history of bladder cancer five years before her presentation and which was treated with subtotal bladder resection, and a cerebral hemorrhage 25 years ago for which surgery was performed. She suffered from systemic hypertension and had been receiving antihypertensive medication for 25 years. Preoperative laboratory investigations (normal range) showed a hemoglobin level of $14.8 \mathrm{~g} / \mathrm{dL}(11.3-16.1)$, alanine aminotransferase (ALT) $65 \mathrm{U} / \mathrm{L}$ (5 - 45), aspartate aminotransferase (AST) $45 \mathrm{U} / \mathrm{L}$ ( 5 - 40), alkaline phosphatase $61 \mathrm{U} / \mathrm{L}(30-110)$, total bilirubin $0.68 \mathrm{mg} / \mathrm{dL}(0.2$ 1.2), high density lipoprotein (HDL) $46 \mathrm{mg} / \mathrm{dL}$ (32 - 71), low density lipoprotein (LDL) $142 \mathrm{mg} / \mathrm{dL}(0$ - 137), and creatinine $0.92 \mathrm{mg} / \mathrm{dL}(0.6$ - 1.4).

On the day of the surgery, the patient received atropine $0.5 \mathrm{mg}$ and midazolam $1.5 \mathrm{mg}$ as premedication. Monitors included ECG, heart rate (HR), non-invasive blood pressure (BP), blood oxygen saturation $\left(\mathrm{SpO}_{2}\right)$, and end- 
tidal $\mathrm{CO}_{2}$. Her pre-anesthetic vital signs were BP 130/82 $\mathrm{mmHg}$, $\mathrm{HR} 73 \mathrm{bpm}$, and $\mathrm{SpO}_{2} 96 \%$. General anesthesia was induced with remifentanil $0.5 \mu \mathrm{g} / \mathrm{kg} / \mathrm{min}$ and propofol $80 \mathrm{mg}$ IV. After the loss of eyelash reflex was confirmed, neuromuscular monitoring began immediately. For the calibration of acceleromyography (TOF-Watch $\mathrm{SX}^{\circledR}$, Organon Ltd., Dublin, Ireland), a 5-s 50-Hz supramaximal tetanic stimulus was administered over both ulnar nerves [6]. A supramaximal current was obtained after the initial single twitch calibration. After stabilization of control responses, rocuronium $30 \mathrm{mg}(0.43 \mathrm{mg} / \mathrm{kg})$ was administered due to an estimated short surgical time, and tracheal intubation was performed at the disappearance of the TOF response. Anesthesia was maintained with desflurane $6 \%$ by volume in $50 \%$ oxygen-enriched air and remifentanil $0.2 \mu \mathrm{g} / \mathrm{kg} / \mathrm{min}$, and this mixture was titrated to maintain a bispectral index (BIS) of approximately 40 . At 45 minutes after induction of anesthesia, the patient bucked in response to surgical traction, so rocuronium $10 \mathrm{mg}$ was injected. At that time, the TOF response showed three twitches. The surgical procedure ended 10 minutes after receiving the last dose of rocuronium. The neuromuscular block was antagonized with glycopyrrolate $0.4 \mathrm{mg}$ and pyridostigmine $10 \mathrm{mg} \mathrm{IV}$, when one twitch was shown at TOF stimulation. Fifteen minutes passed after the reversal with no indication that the patient was recovering from the rocuronium-induced NMB. Only one twitch was not changed at TOF stimulation. At that point, a bolus of IV sugammadex $140 \mathrm{mg}$ (2 $\mathrm{mg} / \mathrm{kg}$ ) was injected to remove the residual NMB. A TOF ratio of 1.0 was confirmed by acceleromyography within 2 minutes. Tracheal extubation was performed uneventfully in the operating room. The patient's postoperative recovery course was unremarkable.

\section{Discussion}

The recovery time from rocuronium may be increased in elderly and female patients [7]. Due to this fact and an estimated short surgical time, low-dose rocuronium 30 $\mathrm{mg}(0.43 \mathrm{mg} / \mathrm{kg})$ was injected initially for this patient. However, an additional dose of rocuronium $10 \mathrm{mg}$ was required once the surgical time was prolonged, and the patient began bucking in response to surgical traction. The surgical procedure ended abruptly 10 minutes after receiving the last dose of rocuronium. Initially, we decided to use glycopyrrolate $0.4 \mathrm{mg}$ and pyridostigmine $10 \mathrm{mg}$ IV after the confirmation of one twitch at TOF stimulation, which have an onset of 2 - 5 minutes, a peak activity occurring at about $10-20$ minutes, and a $2-4$ hour duration [8]. After fifteen minutes from the reversal, the TOF response of one twitch was not changed. Pyridostigmine does not achieve complete reversal of muscle blockade compared to neostigmine at $10 \%$ of initial first twitch height during pancuronium-induced NMB [9]. The incidence of residual block (TOF ratio $<0.7$ ) after reversal using pyridostigmine $10 \mathrm{mg}$ is $21.5 \%$ in the recovery room [4]. Moreover, the time to obtain a TOF ratio of 0.9 is extended greatly [10]. Only in Korea pyridostigmine is still used as a reversal agent in clinical practice (more than $80 \%$ ) [11]. We think that the standard of care for reversal of rocuronium-induced NMB in Korea should be changed from pyridostigmine, with its lower potency and slower onset, to neostigmine. The reason of prolonged paralysis after reversal of neuromuscular blockade was not known, but we suspect that the concomitant drugs (local anesthetics, antibiotics, and calcium channel blockers, etc) have also been affected.

Sugammadex is a modified $\gamma$-cyclodextrin that forms tight one-to-one complexes with rocuronium and, to a slightly lesser extent, vecuronium, resulting in rapid termination of NMB [12]. Sugammadex is a fast and predictable dose-dependent reversing agent of any degree of block induced by rocuronium, a property that cannot be replicated with neostigmine/glycopyrrolate [13]. In moderate degrees of neuromuscular block (reappearance of two twitches), significantly faster recovery $(1.5 \mathrm{~min})$ to a TOF ratio of 0.9 occurred after administration of sugammadex $2 \mathrm{mg} / \mathrm{kg}$ compared to neostigmine $50 \mu \mathrm{g} / \mathrm{kg}(18.6$ $\mathrm{min})$ [14]. Sugammadex $(4.0$ and $8.0 \mathrm{mg} / \mathrm{kg})$ reversed profound NMB (post-tetanic count 1 or 2) induced by rocuronium in a mean time of 1.7 minutes [13]. Sugammadex has the potential to be cost-effective compared with neostigmine/glycopyrrolate for the reversal of rocuronium-induced moderate or profound NMB and potentially provides increased patient safety due to the increased predictability of recovery from NMB [15]. In this case, moderate rocuronium-induced NMB was successsfully reversed within 2 minutes with sugammadex at doses of $2 \mathrm{mg} / \mathrm{kg}$. Sugammadex made it possible that the predictable effectiveness of a reversal agent, and which fully prevents residual block, is therefore highly desirable.

\section{REFERENCES}

[1] G. S. Murphy, J. W. Szokol, J. M. Marymont, et al., "Residual Paralysis at the Time of Tracheal Extubation," Anesthesia \& Analgesia, Vol. 100, No. 6, 2005, pp. 18401845.

http://dx.doi.org/10.1213/01.ANE.0000151159.55655.CB

[2] S.-J. Jeong, J.-I. Han, H.-J. Baik, H. Lee, et al., "The Effect of Pyridostigmine on Bispectral Index during Recovery from Sevoflurane Anesthesia," Korean Journal of Anesthesiology, Vol. 61, No. 6, 2011, pp. 460-464. http://dx.doi.org/10.4097/kjae.2011.61.6.460

[3] R. D. Miller, L. S. Van Nyhuis, E. I. Eger 2nd, et al., "Comparative Times to Peak Effect and Durations of Action of Neostigmine and Pyridostigmine," Anesthesiol- 
ogy, Vol. 41, No. 1, 1974, pp. 27-33.

[4] K. S. Kim, S. H. Lew, H. Y. Cho, et al., "Residual Paralysis Induced by Either Vecuronium or Rocuronium after Reversal with Pyridostigmine," Anesthesia \& Analgesia, Vol. 95, No. 6, 2002, pp. 1656-1660.

[5] R. K. Mirakhur. "Sugammadex in Clinical Practice," Anaesthesia, Vol. 64, Suppl. 1, 2009, pp. 45-54. http://dx.doi.org/10.1111/j.1365-2044.2008.05870.x

[6] A. F. Kopman, S. Kumar, M. M. Klewicka, et al., "The Staircase Phenomenon. Implications for Monitoring of Neuromuscular Transmission," Anesthesiology, Vol. 95, No. 2, 2001, pp. 403-407.

[7] R. S. Matteo, E. Ornstein, A. E. Schwartz, et al., "Pharmacokinetics and Pharmacodynamics of Rocuronium (Org 9426) in Elderly Surgical Patients," Anesthesia \& Analgesia, Vol. 77, No. 6, 1993, pp. 1193-1197.

[8] A. Ferguson, P. Egerszegi, D. R. Bevan, et al., "Neostigmine, Pyridostigmine, and Edrophonium as Antagonists of Pancuronium," Anesthesiology, Vol. 53. No. 5, 1980, pp. 390-394.

[9] F. Donati, J. Lahoud, D. McCready, et al., "Neostigmine, Pyridostigmine and Edrophonium and Neostigmine as Antagonists of Deep Pancuronium Blockade," Canadian Journal of Anaesthesia, Vol. 34, No. 6, 1987, pp. 589593.

[10] A. Y. Oh, S. D. Kim and C. S. Kim, "Early and Late Reversal of Rocuronium with Pyridostigmine during Sevoflurane Anaesthesia in Children," Anaesthesia and Intensive Care, Vol. 32, No. 5, 2004, pp. 649-652.
[11] S. J. Jeong, J. I. Han, H. J. Baik, et al., "The Effect of Pyridostigmine on Bispectral Index during Recovery from Sevoflurane Anesthesia," Korean Journal of Anesthesiology, Vol. 61, No. 6, 2011, pp. 460-464. http://dx.doi.org/10.4097/kjae.2011.61.6.460

[12] A. Abrishami, J. Ho, J. Wong, et al., "Cochrane Corner: Sugammadex, a Selective Reversal Medication for Preventing Postoperative Residual Neuromuscular Blockade," Anesthesia \& Analgesia, Vol. 110, No. 4, 2010, p. 1239.

[13] S. B. Groudine, R. Soto, C. Lien, et al., "A Randomized, Dose-Finding, Phase II Study of the Selective Relaxant Binding Drug, Sugammadex, Capable of Safely Reversing Profound Rocuronium-Induced Neuromuscular Block," Anesthesia \& Analgesia, Vol. 104, No. 3, 2007, pp. 555-562. http://dx.doi.org/10.1213/01.ane.0000260135.46070.c3

[14] M. Blobner, L. I. Eriksson, J. Scholz, et al., "Reversal of Rocuronium-Induced Neuromuscular Blockade with Sugammadex Compared with Neostigmine during Sevoflurane Anaesthesia: Results of a Randomised, Controlled Trial," European Journal of Anaesthesiology, Vol. 27. No. 10, 2010, pp. 874-881. http://dx.doi.org/10.1097/EJA.0b013e32833d56b7

[15] F. Paton, M. Paulden, D. Chambers, et al., "Sugammadex Compared with Neostigmine/Glycopyrrolate for Routine Reversal of Neuromuscular Block: A Systematic Review and Economic Evaluation," British Journal of Anaesthesia, Vol. 105, No. 5, 2010, pp. 558-567. http://dx.doi.org/10.1093/bja/aeq269 